\title{
Urogenital Chlamydia trachomatis in Gabon: an unrecognised epidemic
}

\author{
A LECLERC, E FROST, M COLLET, J GOEMAN, L BEDJABAGA \\ From the Centre International de Recherches Médicales de Franceville, Franceville, Gabon
}

SUMMARY Samples from 218 men with urethritis, 517 women with pelvic pain or pelvic pain and vaginal discharge, 218 women consulting for infertility, and 598 postpartal women were screened for Chlamydia trachomatis by culture and direct immunofluorescence. Chlamydiae were detected in $18 \%$ $(39 / 218)$ of the men, $18 \%(45 / 252)$ of women with vaginal discharge, $14 \%(38 / 265)$ of those with pelvic pain, $10 \%(21 / 218)$ of infertile, and $10 \%(59 / 598)$ of postpartal women. A chlamydial prevalence of $18 \%$ (41) was observed in 229 postpartal women aged under 21 , whereas only $5 \%$ (10) of 360 postpartal women over 21 had $C$ trachomatis. In the other clinical groups, an age related decrease in prevalence was noted in women over 25 . The direct immunofluorescence test correlated well with culture. The small difference in isolation between symptomatic and postpartal women indicates that women in this population do not seek medical attention for chlamydial infections and expose themselves to chlamydial salpingitis and infertility.

Chlamydia trachomatis is one of the most common sexually transmitted pathogens in Europe and America. Very few studies, however, have been undertaken in Africa, ${ }^{1-6}$ Asia, or South America, no doubt largely because facilities are not available for growing the organism in tissue culture. The recent advent of direct immunofluorescence ${ }^{7}$ and immunoenzymatic ${ }^{8}$ detection procedures provides less complicated, albeit still very expensive, alternatives.

An indirect method of estimating chlamydial prevalence is to assess the prevalence of non-gonococcal urethritis (NGU). Whereas NGU is more common than gonorrhoea in Europe and North America, many studies from Africa have shown that about $70 \%$ of urethritis was gonococcal, ${ }^{29-11}$ whereas studies of ophthalmia neonatorum from the same or neighbouring countries indicated that $C$ trachomatis was observed as often as Neisseria gonorrhoeae. ${ }^{24612}$

In a semirural community in Central Africa we screened for $C$ trachomatis using culture and immunofluorescence in men and women consulting for genitourinary discharge and in women presenting for other reasons.

\footnotetext{
Address for reprints: Dr E Frost, Département de Microbiologie, Centre Hospitalier Universitaire, Sherbrooke, Quebec, Canada J1H $5 \mathrm{~N} 4$

Accepted for publication 31 December 1987
}

\section{Patients and methods}

We studied the following patients, who all presented at the Hôpital Provincial de Franceville: 218 men with clinical symptoms of urethritis; 517 women with gynaecological complaints, 252 with vaginal discharge and 265 with both pelvic pain and vaginal discharge; 218 women consulting for infertility; and 598 women who had given birth two or three days previously.

We obtained samples from men with a cotton on wire swab (Entuswab, MW142, Medical Wire, Potley, Corsham, Wiltshire, UK), which was inserted 2 or $3 \mathrm{~cm}$ into the urethra, rotated, and withdrawn. The specimen was then applied to a microscope slide with one $8 \mathrm{~mm}$ well by rolling the swab within the well perimeter. A second swab was taken in the same way, and the tip was cut off into 2SP transport medium.

After first removing excess secretions, we took samples from women (under direct vision) with an Entuswab, which was inserted into the endocervical canal, rotated, withdrawn without touching the walls of the vagina, and applied to a microscope slide as above. Specimens for culture were obtained by rotating a spiral tipped plastic swab (Bactopick, LaboModerne, Paris) in the endocervical canal and then breaking the tip into 2SP transport medium.

Specimens arrived at the laboratory two to three hours later. The slides were then fixed with methanol and stored at $4^{\circ} \mathrm{C}$ before being stained, and the 2SP 
Table 1 Detection of Chlamydia trachomatis in urogenital samples by culture immunofluorescence (IF)

\begin{tabular}{|c|c|c|c|}
\hline & \multicolumn{3}{|c|}{ Proportion (\%) positive by } \\
\hline & Culture & IF & Culture or IF \\
\hline $\begin{array}{l}\text { Men }(n=92) \\
\text { Women with: } \\
\text { Discharge }(n=252) \\
\text { Pelvic pain and discharge }(n=265) \\
\text { Infertile women }(n=218) \\
\text { Postpartal women }(n=598)\end{array}$ & $\begin{array}{l}13 / 83(15 \cdot 7) \\
28 / 206(13 \cdot 6) \\
24 / 223(10 \cdot 8) \\
14 / 198(7 \cdot 0) \\
48 / 574(8 \cdot 3)\end{array}$ & $\begin{array}{l}14 / 92(15 \cdot 2) \\
40 / 252(15 \cdot 9) \\
33 / 259(12 \cdot 7) \\
18 / 209(8 \cdot 6) \\
57 / 598(9 \cdot 5)\end{array}$ & $\begin{array}{l}15 / 92(16 \cdot 3) \\
45 / 252(17 \cdot 9) \\
38 / 265(14 \cdot 3) \\
21 / 218(9 \cdot 6) \\
59 / 598(9 \cdot 9)\end{array}$ \\
\hline
\end{tabular}

transport media were vigorously shaken and then frozen at $-70^{\circ} \mathrm{C}$ before culture.

$C$ trachomatis detection procedures were as follows: the immunofluorescence slide was stained with a monoclonal antibody directed against $C$ trachomatis (MicroTrak-Syva BioMérieux) and examined with a fluorescence microscope. Samples were considered to be positive if at least 10 round, apple-green, fluorescent particles were counted.

Specimens in 2SP transport medium were thawed before being sonicated, inoculated by centrifugation, cultured in McCoy cells grown in 96 well plates with two wells a sample, and incubated in medium with cycloheximide for 72 hours. Inclusions were shown with immunoperoxidase using human serum containing antibodies to $C$ trachomatis. ${ }^{12}$

\section{Results}

SYMPTOMATIC MEN

Of 92 men tested by both culture and immunofluorescence, $C$ trachomatis was cultured from $13(16 \%)$ of 83 (table 1) and detected by immunofluorescence in a further two of nine whose cultures were contaminated. Of the 13 culture positive men, one was not detected by immunofluorescence, but no immunofluorescence positive samples were culture negative. Analysis of a further 126 men with urethritis by culture only yielded 24 positive results, which gave a prevalence of $18 \%$ in the 218 men.

SYMPTOMATIC WOMEN

Of 252 women presenting with vaginal discharge screened for $C$ trachomatis by culture and immuno- fluorescence, $46(18 \%)$ yielded contaminated cultures. Positive results were obtained by culture in $14 \%$ (28/ $206)$, by immunfluorescence in $16 \%(40 / 252)$, and by either immunofluorescence or culture in $18 \%(45 / 252)$ (table 1).

Of 265 women presenting with pelvic pain and vaginal discharge, $11 \%(24 / 223)$ were culture positive, $13 \%(33 / 259)$ were immunofluorescence positive, and $14 \%(38 / 265)$ were positive by either culture or immunofluorescence (table 1). Culture specimens from $42(16 \%)$ were contaminated, but eight $(19 \%)$ of them were immunofluorescence positive.

\section{OTHER WOMEN}

Two groups of women being examined by a gynaecologist for other reasons than vaginal discharge were screened for $C$ trachomatis. The first group consisted of 218 women consulting for infertility, and the second comprised 598 postpartal women (table 1). Positive culture results were found in 7\% (14/198) infertile women and $8 \%(48 / 574)$ postpartal women, while the respective percentages immunofluorescence positive were $9 \%(18 / 209)$ and $10 \%(57 / 598)$, and immunofluorescence or culture positives were $10 \%$ $(21 / 218)$ and $10 \%(59 / 598)$. Fewer cultures were contaminated in these two groups $(9 \%(20 / 218)$ and $4 \%(24 / 598)$ respectively) than in the symptomatic women, but again many of these were immunofluorescence positive $(25 \%$ (five) and $33 \%$ (eight), respectively).

CORRELATION OF AGE WITH CHLAMYDIAL

PREVALENCE

We knew the ages of many of the women. Dividing the

Table 2 Prevalence of Chlamydia trachomatis in women of different age groups

\begin{tabular}{|c|c|c|c|}
\hline \multirow[b]{2}{*}{ Clinical presentation } & \multicolumn{3}{|c|}{ Proportion (\%) positive aged } \\
\hline & $<21$ years & $21-25$ years & $>25$ years \\
\hline $\begin{array}{l}\text { Discharge } \\
\text { Pelvic pain } \\
\text { Infertile } \\
\text { Postpartal }\end{array}$ & $\begin{array}{c}16 / 50(32) \\
10 / 48(21) \\
5 / 27(19) \\
41 / 229(18)\end{array}$ & $\begin{array}{l}14 / 67(21) \\
14 / 68(21) \\
12 / 79(15) \\
10 / 189(5)\end{array}$ & $\begin{array}{l}6 / 65(9) \\
6 / 79(8) \\
4 / 78(5) \\
8 / 171(5)\end{array}$ \\
\hline
\end{tabular}


Table 3 Sensitivity, specificity, positive predictive value, negative predictive value, and overall agreement of immunofluorescence with culture in detecting Chlamydia trachomatis (numbers given in table 1)

\begin{tabular}{|c|c|c|c|c|c|}
\hline & $\begin{array}{l}\text { Sensitivity } \\
(\%)\end{array}$ & $\begin{array}{l}\text { Specificity } \\
(\%)\end{array}$ & $\begin{array}{l}\text { Positive predictive } \\
\text { value }(\%)\end{array}$ & $\begin{array}{l}\text { Negative predictive } \\
\text { value }(\%)\end{array}$ & $\begin{array}{l}\text { Overall agreement } \\
\text { with culture (\%) }\end{array}$ \\
\hline $\begin{array}{l}\text { Men } \\
\text { Women with: }\end{array}$ & 92 & 100 & 100 & 98 & 99 \\
\hline $\begin{array}{l}\text { Discharge } \\
\text { Pelvic pain } \\
\text { Infertile women } \\
\text { Postpartal women }\end{array}$ & $\begin{array}{l}82 \\
79 \\
77 \\
93\end{array}$ & $\begin{array}{l}97 \\
97 \\
98 \\
99\end{array}$ & $\begin{array}{l}79 \\
76 \\
77 \\
93\end{array}$ & $\begin{array}{l}97 \\
97 \\
98 \\
99\end{array}$ & $\begin{array}{l}95 \\
96 \\
97 \\
98\end{array}$ \\
\hline
\end{tabular}

population into groups of women younger than 21, 21 to 25 , or over 25 showed that women over 25 with discharge, pelvic pain, or infertility had fewer chlamydial infections than the younger women, but postpartal women aged 21 to 25 had a similar prevalence to those over 25 and a significantly $(p<0.05)$ lower prevalence than those under 21 (table 2). The chlamydial prevalence in postpartal women aged 21 to 25 was significantly ( $p<0.01$ ) lower than in women of the same age presenting with other conditions (table 2).

\section{CULTURE VERSUS IMMUNOFLUORESCENCE TO}

\section{DETECT C TRACHOMATIS}

Immunofluorescence compared with culture to detect $C$ trachomatis had a sensitivity of $92 \%$ and a specificity of $99 \%$ in postpartal women and men with urethritis, whereas in symptomatic and infertile women the sensitivity was between $77 \%$ and $82 \%$ and the specificity about $97 \%$ (table 3 ).

Numbers of fluorescent particles seen by immunofluorescence compared with numbers of inclusions seen in cultures showed that $75 \%(15 / 20)$ of immunofluorescence samples with more than 1000 particles had over 20 inclusions on culture, whereas over 20 inclusions were found in only $23 \%(17 / 75)$ of samples with fewer particles by immunofluorescence. Furthermore, most $(89 \%(16 / 18))$ of the culture negative immunofluorescence positive sample and most (58\% (21/36)) cultures with fewer than 10 inclusions had 10 to 100 particles by immunofluorescence (table 4).

Table 4 Correlation between numbers of fluorescent particles seen on immunofluorescence and numbers of inclusions observed on culture (figures are numbers of samples with given numbers of particles and inclusions)

\begin{tabular}{lllll}
\hline \multirow{2}{*}{$\begin{array}{l}\text { Fluorescent } \\
\text { particles }\end{array}$} & \multicolumn{5}{l}{ Inclusions in culture } \\
\cline { 2 - 5 } & 0 & $1-9$ & $10-20$ & $>20$ \\
\hline $10-100$ & 16 & 21 & 6 & 9 \\
$100-1000$ & 2 & 12 & 1 & 8 \\
$>1000$ & 0 & 3 & 2 & 15 \\
\hline
\end{tabular}

\section{Discussion}

We observed a low prevalence of chlamydial isolation in a large sample of men and women with genitourinary discharge. This was surprising considering that $C$ trachomatis have been isolated from the conjunctiva of at least $2 \cdot 7 \%$ of neonates. ${ }^{12}$ Screening two groups of women not presenting for vaginal discharge showed a prevalence of $C$ trachomatis almost as high as that observed in symptomatic women, which indicates that most women with chlamydial infections have no, or very mild, symptoms and do not seek medical attention. This low level of awareness of chlamydial infection must exert a heavy toll on fertility. Indeed, African women have high levels of infection related infertility, ${ }^{13}$ and infertile women have high levels of antichlamydial antibodies. ${ }^{51415}$

As expected, chlamydial prevalence was highest in women aged under $21 .{ }^{16} \mathrm{It}$ is interesting, however, that women aged 21 to 25 who had maintained their fertility had significantly lower chlamydial prevalence than infertile women or women with discharge or pelvic pain. Whether this derives from the inhibitory effect of $C$ trachomatis on fertility or from differences in behaviour between pregnant and non-pregnant women is not clear.

In our analysis of the data we considered both culture and immunofluorescent positive samples as being chlamydia positive because our culture isolation rates were probably suboptimal, as we used 96 well microplates with two wells a sample and without blind passage. ${ }^{1718}$ Furthermore, it was not possible to refrigerate samples during transport from the hospital to the laboratory, which could have reduced chlamydial isolation and increased contamination. ${ }^{19}$ As with other studies, ${ }^{720-26}$ we observed reasonably good correlation between culture and immunofluorescent detection of $C$ trachomatis in all groups. Contaminated samples were more frequently immunofluorescent positive than were the others, particularly in women not presenting for vaginal discharge or pelvic pain.

Funding was provided through contract No M 0351-G of the 
Commission of the European Communities and by the Provision des Investissements Diversifiés of Elf-Gabon and the Government of Gabon.

\section{References}

1 Mirza NB, Nsanze H, D'Costa LJ, Piot P. Microbiology of vaginal discharge in Nairobi, Kenya. British Journal of Venereal Diseases 1983;59:186-8.

2 Mabey DCM, Whittle HC. Genital and neonatal chlamydial infection in a trachoma endemic area. Lancet 1982;ii:300-1.

3 Bentsi C, Klufio CA, Perine PL, et al. Genital infections with Chlamydia trachomatis and Neisseria gonorrhoeae in Ghanaian women. Genitourin Med 1985;61:48-50.

4 Laga M, Nsanze H, Plummer FA, Ndinya-Achola JO, Brunham RC, Piot P. Comparison of tetracycline and silver nitrate for the prophylaxis of chlamydial and gonococcal ophthalmia neonatorum. In: Oriel D, Ridgway G, Schachter J, Taylor-Robinson D, Ward M, eds. Chlamydial infections. Cambridge: Cambridge University Press, 1986:301-4.

5 Ballard RC, Fehler HG, Piot P. Chlamydial infections of the eye and genital tract in developing societies. In: Oriel D, Ridgway G, Schachter J, Taylor-Robinson D, Ward M, eds. Chlamydial infections. Cambridge: Cambridge University Press, 1986: 479-86.

6 Meheus A, Delgadillo R, Widy-Wirski R, Piot P. Chlamydial ophthalmia neonatorum in Central Africa. Lancet 1982;ii:882.

7 Tam M, Stamm WE, Handsfield HH, et al. Culture-independent diagnosis of Chlamydia trachomatis using monoclonal antibodies. $N$ Engl J Med 1984;310:1146-50.

8 Jones MF, Smith TF, Houglum AJ, Herrmann JE. Detection of Chlamydia trachomatis in genital specimens by the Chlamydiazyme test. J Clin Microbiol 1984;20:465-7.

9 Meheus A, Widy-Wirski R, D'Costa J, van Dyck E, Delgadillo R, Piot $P$. Treatment of gonorrhoea in males in the Central African Republic with spectinomycin and procaine penicillin. Bull WHO 1984;62:89-94.

10 Yvert F, Riou JY, Frost E, Ivanoff B. Les infections gonococciques au Gabon (Haut-Ogooué). Pathol Biol (Paris) 1984; 32:80-4.

11 Griffith HB. Gonorrhoea and fertility in Uganda. Eugenics Review 1963;55:103-8.

12 Frost E, Yvert F, Zué Ndong J, Ivanoff B. Ophthalmia neonatorum in a semi-rural African community. Trans $R$ Soc Trop Med Hyg 1987;81:378-80.

13 Cates W, Farley TMM, Rowe PJ. Worldwide patterns of infertility: is Africa different? Lancet 1985;ii:596-8.
14 Mabey DCM, Ogbaselassie G, Robertson JN, Heckels JE, Ward ME. Tubal infertility in the Gambia: chlamydial and gonococcal serology in women with tubal occlusion compared with pregnant controls. Bull WHO 1985;63:1107-13.

15 Frost E, Collet M, Reniers J, Leclerc A, Ivanoff B, Meheus A. Importance of chlamydial antibodies in acute salpingitis in central Africa. Genitourin Med 1987;63:176-8.

16 Mavoungou D, Frost E, Collet M, Gass R, Leclerc A, Peeters M. Sexuality, puberty and sexually transmitted diseases (STD) in young African girls in Gabon. In: Ratnam SS, Teoh E-S, Anandakumar C, eds. Endometriosis. Proceedings of the 5th world congress on fertility and sterility. Carnforth, England: Parthenon Publishing, 1986: vol 5, 139-41.

17 Naughton H, Mallinson H. Microplate culture with PAS staining for the diagnostic isolation of Chlamydia trachomatis. Med Lab Sci 1983;40:193-5.

18 Schachter J. Immunodiagnosis of sexually transmitted disease. Yale J Biol Med 1985;58:443-52.

19 Williams T, Maniar AC, Brunham RC, Hammond GW. Identification of Chlamydia trachomatis by direct immunofluorescence applied to specimens originating in remote areas. $J$ Clin Microbiol 1985;2:1053-4.

20 Uyeda CT, Welborn P, Ellison-Birang N, Shunk K, Tsaouse B. Rapid diagnosis of chlamydial infections with the MicroTrak direct test. J Clin Microbiol 1984;20:948-50.

21 Mallinson H, Turner GC, Carey PB, Khan MH. Rapid detection of Chlamydia trachomatis with monoclonal antibodies. Lancet 1984;i:1180-1.

22 Foulkes SJ, Deighton R, Feeney ARB, Mohanty KC, Freeman CWJ. Comparison of direct immunofluorescence and cell culture for detecting Chlamydia trachomatis. Genitourin Med 1985;61:255-7.

23 Teare EL, Sexton C, Lim F, McManus T, Uttley AHC, Hodgson J. Conventional tissue culture compared with rapid immunofluorescence for identifying Chlamydia trachomatis in specimens from patients attending a genitourinary clinic. Genitourin Med 1985;61:379-82.

24 Quinn TC, Warfield P, Kappus E, Barbacci M, Spence M. Screening for Chlamydia trachomatis infection in an inner-city population: a comparison of diagnostic methods. J Infect Dis 1985;152:419-23.

25 Stamm WE, Harrison HR, Alexander ER, Cles LD, Spence MR, Quinn TC. Diagnosis of Chlamydia trachomatis infections by direct immunofluorescence staining of genital secretions-a multicenter trial. Ann Intern Med 1984;101:638-41.

26 Lipkin ES, Moncada JV, Shafer MA, Wilson RE, Schachter J. Comparison of monoclonal antibody staining and culture in diagnosing cervical chlamydial infection. $J$ Clin Microbiol 1986;23:114-7. 